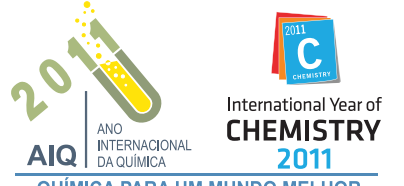

\title{
ISOLAMENTO E SELEÇÃO DE MICRO-ORGANISMOS RESISTENTES E CAPAZES DE VOLATILIZAR MERCÚRIO
}

\author{
Patricia Giovanella e Fátima Bento \\ Departamento de Microbiologia, Instituto de Ciências Básicas da Saúde, Universidade Federal do Rio Grande do Sul, Rua Sarmento \\ Leite, 500, 90050-170 Porto Alegre - RS, Brasil \\ Lucélia Cabral, Clesio Gianello e Flávio Anastácio Oliveira Camargo* \\ Departamento de Ciência do Solo, Universidade Federal do Rio Grande do Sul, Av. Bento Gonçalves, 7712, 91540-000 Porto Alegre \\ - RS, Brasil
}

Recebido em 18/2/10; aceito em 10/9/10; publicado na web em 30/11/10

\begin{abstract}
ISOLATION AND SELECTION OF MICROORGANISMS RESISTANT AND ABLE TO VOLATILIZE MERCURY. Mercury (Hg) occurs in the environment as a natural and anthropogenic element, and through the years the accumulation of mercury has affected the integrity of ecosystems and human health. This study presents a screening of microorganisms resistant to organic and inorganic mercury, the determination of the minimum inhibitory concentration of $\mathrm{Hg}$, the estimation of the mercury volatilization by selected microorganisms and the dynamics of volatilization. Eight Gram-negative bacteria resistant to high concentrations of mercury (60 to $210 \mathrm{mg} \mathrm{L}^{-1}$ ) were selected, and these isolates showed ability to volatilize the metal. The dynamics of the volatilization of the Proteus mirabilis M50C demonstrated that in only $4 \mathrm{~h}$ of incubation it was possible to volatilize $72 \%$ of the mercury present in the culture. The results showed promising application for bioremediation strategies.
\end{abstract}

Keywords: bacterial resistance to mercury; mercury chloride; minimum inhibitory concentration.

\section{INTRODUÇÃO}

O mercúrio ocorre naturalmente no ambiente em diferentes espécies químicas com solubilidade, reatividade e toxicidade distintas, causando diferentes impactos no ecossistema e na saúde do homem. ${ }^{1}$ Este metal é raramente encontrado como elemento livre na natureza, estando em baixas concentrações e amplamente distribuído por toda crosta terrestre. As fontes mais importantes para extração de mercúrio são as reservas de minério de cinábrio $(\mathrm{HgS})$, o qual é encontrado em rochas de regiões onde existe atividade vulcânica recente, em fraturas minerais e em áreas próximas de fontes de águas termais. ${ }^{2}$

O mercúrio é emitido para o ambiente por inúmeras fontes naturais e antropogênicas, por meio de combinações complexas, envolvendo reações químicas, físicas e biológicas. As fontes antrópicas mais frequentes de mercúrio são as indústrias petroquímicas, eletrônicas, equipamentos de medição, tintas e cloro-soda; além da utilização na extração de ouro e como amálgamas dentárias. ${ }^{3}$

Em humanos, os efeitos renais e neurotóxicos devem ser considerados como os mais importantes numa avaliação de risco pela exposição aos compostos de mercúrio inorgânico. Os sinais e sintomas da ação tóxica do mercúrio no sistema nervoso central consistem basicamente em tremores, depressão, insônia, dificuldade para concentração, diminuição da memória e fobias. A exposição ao mercúrio por longos períodos, mesmo em baixas concentrações pode causar danos renais irreversíveis e afetar o sistema imunológico..$^{4-6}$

A propriedade química mais importante que explica grande parte dos danos biológicos causados pelo mercúrio é a elevada afinidade que este metal possui pelo grupo sulfidrila das proteínas, causando inativação enzimática e desestruturação proteica. Quando o enxofre

*e-mail: fcamargo@ufrgs.br está presente fazendo a ponte peptídica de proteínas, o mercúrio divalente substitui o átomo de hidrogênio para formar mercaptanos. Desse modo, mesmo em baixas concentrações no organismo, o mercúrio interfere no metabolismo e funções celulares. ${ }^{6}$

Apesar de o mercúrio ser tóxico, tanto para células eucarióticas quanto para procarióticas, alguns micro-organismos apresentam mecanismos de resistência a este metal. Entre eles podem-se destacar bombas de efluxo, quelação por polímeros enzimáticos, precipitação, biometiliação e redução enzimática $;{ }^{7}$ o último relacionado ao operon mer. Bactérias que possuem operon mer são capazes de reduzir enzimaticamente o mercúrio (II) para a forma volátil e menos tóxica de mercúrio $\mathrm{Hg}^{\mathrm{o}}{ }^{8,9}$ Essa resposta dos micro-organismos ao $\mathrm{Hg}$, representa um recurso para a remediação de áreas contaminadas por este metal. A remediação de ambientes contaminados com cátions metálicos tóxicos tem empregado convencionalmente, técnicas físico-químicas que incluem precipitação, filtração e recuperação eletroquímica bem como separação por membrana; escavação, depósito de resíduos em aterros sanitários ou, ainda, recobrimento do sítio contaminado. Essas técnicas são pouco eficazes por não remediarem efetivamente o ambiente contaminado e por apresentarem baixa competitividade econômica. ${ }^{10}$ Desta forma, o estudo e desenvolvimento de métodos alternativos de tratamento de efluentes e solos contaminados por este metal, que aliem possibilidade de aplicação em áreas extensas, baixo custo de operação e eficiência de remoção de $\mathrm{Hg}$ (II), é de extrema importância.

Este estudo teve como objetivos selecionar micro-organismos resistentes ao mercúrio (II) e acetato de mercúrio a partir de resíduos industriais contendo $\mathrm{Hg}$; determinar a concentração inibitória mínima de $\mathrm{Hg}$ para interromper o crescimento celular dos isolados; estimar a capacidade dos micro-organismos selecionados em volatilizar mercúrio (II) e conhecer a dinâmica da volatilização do mercúrio durante o crescimento celular de Proteus mirabilis M50C. 


\section{PARTE EXPERIMENTAL}

Para o isolamento de micro-organismos resistentes a mercúrio foram coletadas amostras de lodo $(\mathrm{M})$ e efluente líquido $(\mathrm{C})$ do Sistema de Tratamento de Resíduos do Laboratório de Análise de Solos da UFRGS (STELAS). A técnica utilizada para o isolamento desses micro-organismos foi a de enriquecimento, onde $0,1 \mathrm{gr}$ das amostras de resíduo ou $0,1 \mathrm{~mL}$ de efluente líquido foram adicionados a $20 \mathrm{~mL}$ de meio Luria Bertani (LB), suplementado com doses crescentes de mercúrio $\left(25,50\right.$ e $\left.100 \mathrm{mg} \mathrm{L}^{-1}\right)$ na forma de $\mathrm{HgCl}_{2}$, sendo incubadas por $24 \mathrm{~h}$, sob agitação de $100 \mathrm{rpm}$ a $30 \pm 2{ }^{\circ} \mathrm{C}$. Após este período foi realizada a transferência de $1 \mathrm{~mL}$ da cultura microbiana para outro frasco que continha o mesmo meio e as mesmas concentrações de $\mathrm{HgCl}_{2}$, e então incubada por $24 \mathrm{~h}$ a $30 \pm 2{ }^{\circ} \mathrm{C}$ sob agitação (esta etapa foi repetida 3 vezes). Posteriormente, foram realizadas diluições e inoculação em ágar nutritivo suplementado com $\mathrm{HgCl}_{2}$. As placas foram incubadas a $30 \pm 2{ }^{\circ} \mathrm{C}$ até o aparecimento das colônias, que foram isoladas conforme características morfológicas. ${ }^{11,12}$

Os isolados foram identificados com base no sequenciamento parcial da região $16 \mathrm{~S}$ ribossomal. Os oligonucleotídeos iniciadores universais utilizados para bactérias foram o $27 \mathrm{~F}$ (5'-AGATTTGATCMTGGCTCAG-3') e 1492R (5' - TACGGYTACCTTGTTACGACTT-3'), para a amplificação em PCR. A reação de amplificação foi baseada em Sambrook, ${ }^{13} \mathrm{com}$ algumas modificações para aumentar a eficiência da amplificação, seguindo o seguinte protocolo: tampão de reação (50 mM Tris- $\mathrm{HCl}, \mathrm{pH} 9,0,50 \mathrm{mM} \mathrm{KCl,} \mathrm{2,5 \%} \mathrm{Triton} \mathrm{X} \mathrm{100),}$ dNTPS (200 $\mu \mathrm{M}$ de cada), $0,2 \mu \mathrm{M} \mathrm{MgCl}_{2}, 0,25 \mu \mathrm{M}$ de cada primer, $0,8 \mathrm{ng} / \mu \mathrm{L}$ de DNA das amostras e $0,02 \mathrm{U}$ de Taq DNA polimerase. A amplificação foi realizada em termociclador MJ Research Inc. Watertown, MA, USA e o programa básico constou de 35 ciclos (desnaturação inicial $95^{\circ} \mathrm{C}$ por $5 \mathrm{~min}$; desnaturação subsequente, $95^{\circ} \mathrm{C}$ por $30 \mathrm{~s}$; anelamento, $50{ }^{\circ} \mathrm{C}$ por $1 \mathrm{~min}$; extensão, $72^{\circ} \mathrm{C}$ por 1 min e extensão final por $5 \mathrm{~min}){ }^{14}$

Os produtos de PCR foram purificados através do método padrão de precipitação com PEG 8000 (polietilinoglicol). As reações de sequenciamento dos fragmentos de PCR utilizaram os kits de terminadores marcados da GE Healthcare com oligonucleotídeo iniciador 519r (5'-GWATTACCGCGGCKGCTG-3'). As reações foram lidas em sequenciador automático de DNA no Centro de Biologia Genômica e Molecular da PUCRS e todas as sequências geradas foram submetidas ao banco de dados Genbank/NCBI. ${ }^{15}$

Todos os isolados foram avaliados quanto à concentração inibitória mínima, seguindo a metodologia de Ball ${ }^{12}$ com modificações: em meio de cultura LB contendo mercúrio nas concentrações de 30 a 300 mg L ${ }^{-1}$ na forma de $\mathrm{HgCl}_{2} \mathrm{e} \mathrm{C}_{4} \mathrm{H}_{6} \mathrm{HgO}_{4}$, os isolados foram incubados por até $72 \mathrm{~h}$ a $30 \pm 2{ }^{\circ} \mathrm{C}$ sob agitação de $100 \mathrm{rpm}$. O crescimento foi avaliado visualmente após 24,48 e 72 h de incubação pela turvação do meio. Meio apresentando pouca turvação foi considerado (+), turvação média $(++)$ e muito turvo (+++). A concentração de mercúrio capaz de interromper o crescimento microbiano (meio sem turvação) foi considerada a concentração inibitória mínima deste metal, em relação ao micro-organismo avaliado.

$\mathrm{O}$ crescimento microbiano foi quantificado segundo metodologia adaptada de Miles e colaboradores ${ }^{16} \mathrm{O}$ pré-inóculo foi feito a partir de uma alçada de cada bactéria inoculada em meio LB, contendo 2 mg L ${ }^{-1}$ de $\mathrm{Hg}$ na forma de $\mathrm{HgCl}_{2}$ e incubado por $24 \mathrm{~h}$ a $30 \pm 2{ }^{\circ} \mathrm{C}$ sob agitação de $100 \mathrm{rpm}$. Dessa suspensão bacteriana foi retirada a quantidade de cultura necessária para se obter uma absorbância entre 0,05 e 0,45 a $600 \mathrm{~nm}$ em meio LB. Então, foram realizadas diluições seriadas e $100 \mu \mathrm{L}$ foram aplicados em placas contendo ágar nutriente ( 3 repetições), incubadas por 24 h a $30 \pm 2{ }^{\circ} \mathrm{C}$. Após este período foi realizada contagem de unidades formadoras de colônia (UFC/mL). A leitura da absorbância em espectrofotômetro no comprimento de onda
$600 \mathrm{~nm}$, que correspondeu a aproximadamente $2 \times 10^{7} \mathrm{UFC} / \mathrm{mL}$, nos diferentes isolados foi padronizada para os experimentos posteriores.

A determinação de mercúrio remanescente nas amostras foi realizada pelo Laboratório de Análise de Solos da UFRGS, utilizando o método de espectrofotometria de absorção atômica/geração de vapor frio. $\mathrm{O}$ equipamento utilizado para este experimento foi da marca Perkin Elmer (Analyst 100). Inicialmente, $100 \mu \mathrm{L}$ da amostra foram tratados com uma mistura oxidante contendo $5 \mathrm{~mL}$ de $\mathrm{H}_{2} \mathrm{SO}_{4}$ (98\%), 2 mL de $\mathrm{HNO}_{3}(65 \%)$ e $10 \mathrm{~mL}$ de uma solução de $\mathrm{KMnO}_{4}$ $\left(70 \mathrm{~g} \mathrm{~L}^{-1}\right)$. Após esse procedimento, a mistura foi submetida à temperatura de $121^{\circ} \mathrm{C}$ e $1,5 \mathrm{~atm}$ por $15 \mathrm{~min}$. Em seguida, adicionaram-se $50 \mathrm{~mL}$ de água deionizada e $6 \mathrm{~mL}$ de $\mathrm{ClNH}_{2} \mathrm{OH}_{2}\left(100 \mathrm{~g} \mathrm{~L}^{-1}\right)$. Então o mercúrio foi convertido à forma de $\mathrm{Hg}^{0}$ pelo tratamento com uma solução de $\mathrm{SnCl}_{2}\left(50 \mathrm{~g} \mathrm{~L}^{-1}\right)$. O mercúrio elementar foi arrastado para uma célula de quartzo acoplada ao espectrofotômetro de absorção atômica, através do borbulhamento com uma corrente de gás inerte $\left(\mathrm{N}_{2}\right)$. Completou-se a análise com a medida da absorbância, pela passagem da mistura do gás de arraste com o vapor de $\mathrm{Hg}$ na célula de quartzo no comprimento de onda de $253,7 \mathrm{~nm} .{ }^{17}$

Para avaliar a capacidade de volatilização de mercúrio pelos isolados foi feito um pré-inóculo e a padronização da quantidade de UFC/mL, como descrito anteriormente. Este ensaio foi realizado segundo metodologia de Kannan, ${ }^{18}$ modificada. Em meio de cultura LB contendo $2 \mathrm{mg} \mathrm{L}^{-1}$ de mercúrio na forma de $\mathrm{HgCl}_{2}$, os isolados foram mantidos por $24 \mathrm{~h}$ a $30 \pm 2{ }^{\circ} \mathrm{C}$ sob agitação de $100 \mathrm{rpm}$. Após o período de incubação, foi realizada a determinação do mercúrio remanescente por espectrofotometria de absorção atômica. Para avaliar a volatilização do mercúrio e curva de crescimento de Proteus mirabilis M50C, na presença e na ausência de $\mathrm{Hg}$, foi realizado um ensaio, nas mesmas condições descritas acima, porém com leituras da densidade óptica a $600 \mathrm{~nm}$ nos tempos $0,4,8,12,18$ e $24 \mathrm{~h}$. Nestes mesmos intervalos de tempo, amostras de meio de cultura foram removidas para se avaliar a quantidade remanescente de mercúrio e analisadas por espectrofotometria de absorção atômica.

Todos os resultados obtidos foram produzidos em triplicata e submetidos à análise de variância, desvio padrão e teste de média (Tukey), quando significativo $(\mathrm{p}<0,05)$, utilizando-se o programa estatístico Systat 11. ${ }^{19}$

\section{RESULTADOS E DISCUSSÃO}

Foram isoladas 8 bactérias provenientes do lodo e efluente líquido do Sistema de Tratamento de Resíduos do Laboratório de Análise de Solos da UFRGS (STELAS) (Tabela 1). Pelo sequenciamento da região $16 \mathrm{~S}$ ribossomal foi possível identificar 4 isolados do gênero Pseudomonas, 2 Enterobacter, um Proteus e um Serratia. Trabalhos têm demonstrado que bactérias do gênero Pseudomonas possuem alta resistência a diferentes formas de mercúrio. ${ }^{20-24}$ As bactérias deste gênero também têm sido relatadas em maior abundância em relação a outros gêneros quando em resíduos contendo altas concentrações de $\mathrm{Hg} .{ }^{25}$

A resistência ao mercúrio é frequente entre micro-organismos Gram-negativos. Nakamura e colaboradores ${ }^{26}$ ao isolarem 55 bactérias resistentes a mercúrio, verificaram que somente 4 isolados eram Gram-positivos. Entre os Gram-negativos, 13 eram do gênero Enterobacter. Os gêneros Proteus e Serratia são mencionados com menor frequência na literatura entre as bactérias resistentes ao $\mathrm{Hg}$, do mesmo modo que neste trabalho. Ainda assim, alguns trabalhos associam estes gêneros de bactérias como resistentes ou, ainda, como volatilizadoras de mercúrio. ${ }^{24,27,28}$

$\mathrm{Na}$ análise da concentração inibitória mínima (CIM) foi observado alto nível de resistência em todos os isolados, mas com diferentes capacidades de tolerância (Figura 1). Este resultado indica que a eficiência do sistema de detoxificação de mercúrio pode ser 
Tabela 1. Identificação dos isolados de resíduos provenientes do STELAS líquido (C), STELAS lodo (M), baseada no sequenciamento parcial da região 16S ribossomal

\begin{tabular}{lccc}
\hline Isolado & Espécies mais próximas & $\mathrm{N}^{\mathbf{o}}$ acesso & Similaridade (\%) \\
\hline C50A & Pseudomonas putida & X93997.1 & 100 \\
C50B & Pseudomonas putida & EU239185.1 & 100 \\
M25A & Enterobacter sp. & CP000653.1 & 99 \\
M25B & Enterobacter sp. & DQ985288.1 & 100 \\
M25C & Serratia marcescens & GU220796.1 & 100 \\
M50C & Proteus mirabilis & AM942759.1 & 100 \\
M100A & Pseudomonas delhiensis & FN433047.1 & 99 \\
M100B & Pseudomonas nitrore- & EF107515.1 & 100 \\
& ducens & & \\
\hline \multicolumn{4}{c}{} \\
\hline
\end{tabular}

distinta nos diferentes micro-organismos avaliados. Os isolados que apresentaram as mais baixas resistências a este metal mostraram capacidade de crescimento a uma concentração de $70 \mathrm{mg} \mathrm{L}^{-1}$ para a forma inorgânica divalente e $60 \mathrm{mg} \mathrm{L}^{-1}$ para a forma orgânica acetato de mercúrio. A maioria dos isolados apresentaram uma CIM de 110 $\mathrm{mg} \mathrm{L}^{-1}$ para acetato de mercúrio e acima de $170 \mathrm{mg} \mathrm{L}^{-1}$ para a forma inorgânica divalente, assim como observado por outros autores. ${ }^{12,22,29}$ O micro-organismo mais resistente (M100B) cresceu na presença de $210 \mathrm{mg} \mathrm{L}^{-1} \mathrm{em}$ ambas as formas de mercúrio. Estes resultados concordam com um grupo de pesquisadores, ${ }^{30}$ quando micro-organismos termófilos quimiolitotróficos de uma fonte termal com altas concentrações de $\mathrm{Hg}$ foram avaliados. Deste modo, é possível supor que os micro-organismos avaliados expressaram funções dos genes mer, uma vez que inúmeros trabalhos relacionam a presença deste operon em organismos que possuem alta resistência ao $\mathrm{Hg} .{ }^{11,31,32}$

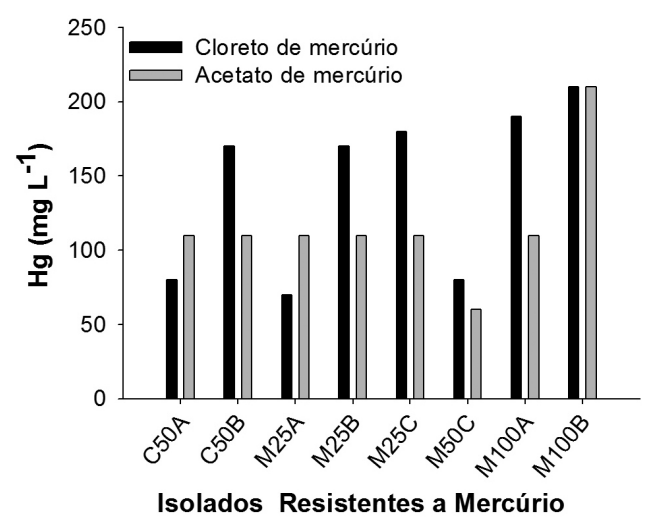

Figura 1. Concentração inibitória mínima (CIM) de $\mathrm{HgCl}_{2}$ e $\mathrm{C}_{4} \mathrm{H}_{6} \mathrm{HgO}_{4}$ sobre os isolados avaliados, após $72 \mathrm{~h}$ de incubação a $30 \pm 2{ }^{\circ} \mathrm{C}$

Como pode ser observado na Figura 2, todos os isolados foram capazes de volatilizar o mercúrio presente no meio de cultura após $24 \mathrm{~h}$ de incubação. Os isolados C50A e M50C foram estatisticamente semelhantes $(\mathrm{p}<0,05)$ na capacidade de volatilizar o $\mathrm{Hg}$, sendo que os percentuais de volatilização apresentados por esses micro-organismos foram maiores que $80 \%$. Um grupo intermediário de 5 micro-organismos (C50B, M25A, M25B, M100A e M100B) foi capaz de volatilizar aproximadamente $70 \%$ do mercúrio presente no meio de cultura. Sadhukham e colaboradores, ${ }^{33}$ quando avaliaram micro-organismos resistentes a mercúrio, obtiveram resultados semelhantes em relação à volatilização de $\mathrm{Hg}$ após $24 \mathrm{~h}$ de incubação. Nesse mesmo trabalho, verificou-se que a capacidade de volatilização dos micro-organismos avaliados estava relacionada aos seus valores de CIM, confirmando os achados de outros autores. ${ }^{34}$ Entretanto, neste estudo esta relação não foi comprovada, pois, no geral, os isolados com as mais baixas CIM apresentaram capacidade superior aos demais em volatilizar o Hg. O contrário foi observado com os isolados C50B, M25B, M100A e M100B, que apesar de terem mostrado as mais altas taxas de tolerância ao $\mathrm{Hg}$, fizeram parte do grupo estatístico que volatilizou aproximadamente $70 \%$. Da mesma maneira, o isolado M25C tem alta resistência ao $\mathrm{Hg}$, porém apresentou capacidade de volatilização muito pequena (30\%) se comparada aos demais isolados.

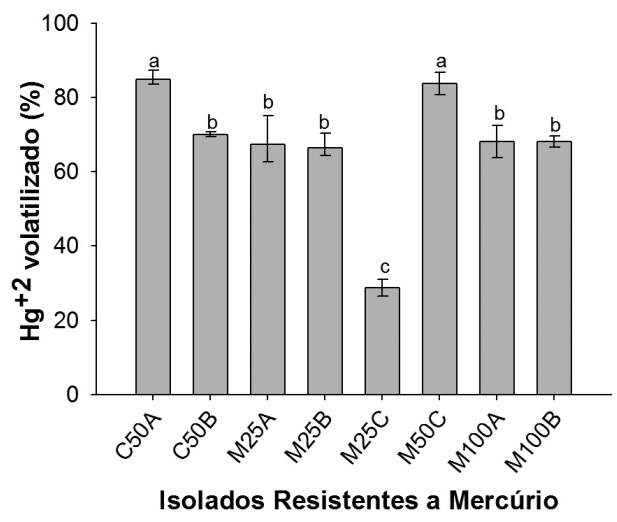

Figura 2. Percentual de volatilização de $\mathrm{Hg}^{2+}$ pelos isolados resistentes a mercúrio, após $24 \mathrm{~h}$ de incubação a $30 \pm 2{ }^{\circ} \mathrm{C}$ na presença de $2 \mathrm{mg} \mathrm{L}^{-1}$ de $\mathrm{HgCl}_{2}$. Pontos representam a média de 3 repetições, as barras o erro padrão e médias com letras iguais não diferem entre os isolados $(p<0,05)$

As divergências aqui encontradas podem ser explicadas possivelmente por fatores como a presença de metalotioneínas em alguns isolados. Estas proteínas possuem resíduos de cisteína e metionina ricos em sulfidrilas, que complexam os metais, protegendo as células da toxicidade destes elementos. ${ }^{35}$ Infelizmente a presença de metalotioneínas não foi avaliada neste estudo, para confirmar esta hipótese. Além disso, é possível que os genes do operon mer não tenham sido induzidos suficientemente pela baixa concentração de $\mathrm{Hg}$ no meio de cultivo dos ensaios, já que a atividade da enzima mercúrio redutase é induzida e não constitutiva. Outra hipótese, é que os micro-organismos analisados possuam diferentes modos de resistência que não foram avaliados neste trabalho.

A Figura 3 apresenta o percentual de volatilização de $\mathrm{Hg}$, nas concentrações 2 e $70 \mathrm{mg} \mathrm{L}^{-1}$ pelo isolado Proteus mirabilis M50C. A capacidade do isolado volatilizar mercúrio teve uma redução significativa $(\mathrm{p}<0,05)$ de $25 \%$, em consequência do aumento da concentração desse metal no meio de cultivo. A presença de altas concentrações de $\mathrm{HgCl}_{2}$ afeta negativamente a capacidade dos micro-organismos volatilizarem, devido ao sequestro intracelular do $\mathrm{Hg}$ por componentes celulares que se ligam ao metal. ${ }^{36}$

Outra possibilidade está relacionada à proteína MerA, pois um dos fatores que afeta a velocidade de uma reação catalisada por enzimas é a quantidade de substrato. A velocidade máxima de reação de uma enzima é atingida quando praticamente todas as moléculas estiverem na forma enzima/substrato e a concentração de enzima livre é insignificante. Neste momento, a enzima está saturada com o substrato e a velocidade de reação não aumenta, mesmo com substrato presente no meio de reação. ${ }^{37}$ Logo, podemos supor que o $\mathrm{Hg}$ presente no meio de cultura poderia estar em excesso em relação ao número de sítios ativos disponíveis da MerA. Consequentemente, maior quantidade de $\mathrm{Hg}$ poderia ter sido volatilizado caso este micro-organismo tivesse sido submetido há um tempo maior de incubação. 


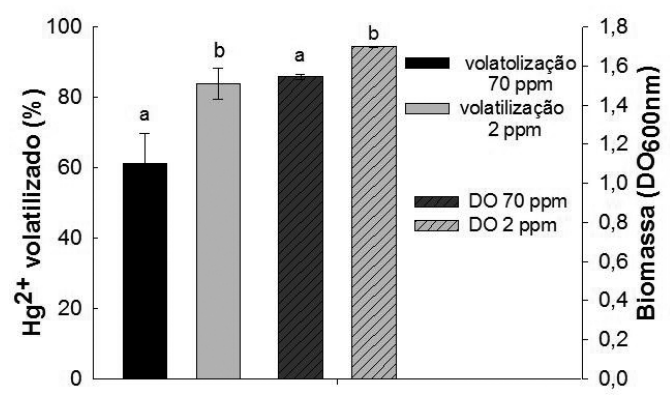

Figura 3. Percentual de volatilização de $\mathrm{Hg}^{2+}$ e formação de biomassa por P. mirabilis $\mathrm{M} 50 \mathrm{C}$ em baixa concentração de $\mathrm{HgCl}_{2}\left(2 \mathrm{mg} \mathrm{L}^{-1}\right)$ e próximo à concentração inibitória mínima $\left(70 \mathrm{mg} \mathrm{L}^{-1}\right)$, após $24 \mathrm{~h}$ de incubação a $30 \pm$ $2{ }^{\circ} \mathrm{C}$. Pontos representam a média de 3 repetições, as barras o erro padrão e médias com letras iguais não diferem entre os isolados $(p<0,05)$

A formação de biomassa de $P$. mirabilis M50C foi $10 \%$ menor em $70 \mathrm{mg} \mathrm{L}^{-1}$ de mercúrio, se comparada à biomassa do isolado na concentração de $2 \mathrm{mg} \mathrm{L}^{-1}$ (Figura 3). A análise estatística aponta diferenças significativas na densidade óptica de $P$. mirabilis M50C na presença de 70 e $2 \mathrm{mg} \mathrm{L}^{-1} \mathrm{de} \mathrm{Hg}$. Outros autores ${ }^{18,33}$ constataram resultados similares aos encontrados neste estudo ao avaliarem a densidade óptica dos isolados em baixas e altas concentrações de mercúrio, e concluíram que a disparidade observada em altas e baixas concentrações de cloreto de mercúrio não foi significativa. Levando em consideração que o isolado avaliado neste ensaio foi submetido à concentração sub-letal de mercúrio e apresentou uma queda de crescimento máxima de $10 \%$, é plausível presumir que biologicamente não existam diferenças.

P. mirabilis M50C foi selecionada para avaliar a dinâmica da redução de cloreto de mercúrio durante o crescimento celular. Este isolado apresentou em $4 \mathrm{~h}$ um rápido aumento de biomassa (Figura 4), tanto na presença como na ausência de $\mathrm{Hg}$, seguindo esse mesmo nível de crescimento até a última leitura da densidade óptica. A remoção de $\mathrm{Hg}$ do meio de cultura foi de $72 \%$ em apenas $4 \mathrm{~h}$ de incubação. Outros autores ${ }^{30,38}$ também observaram que a remoção de $\mathrm{Hg}$ (II) foi precedida de alta formação de biomassa.

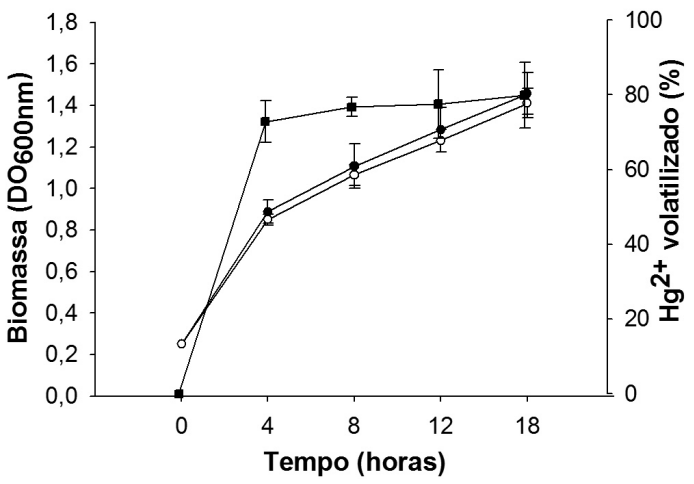

Figura 4. Dinâmica da volatilização de $\mathrm{Hg}^{2+}$ (-) e crescimento microbiano na presença $(\bullet)$ e ausência $(\mathrm{O})$ de $\mathrm{HgCl}_{2}$ pelo isolado P. mirabilis M50C. Pontos representam a média de 3 repetições, as barras o erro padrão e médias com letras iguais não diferem entre os isolados $(p<0,05)$

\section{CONCLUSÕES}

Entre os 8 micro-organismos selecionados resistentes a mercúrio, o gênero Pseudomonas é o mais frequente, seguido do gênero Enterobacter. Todos os isolados apresentaram alta resistência aos compostos de mercúrio ( 60 a $210 \mathrm{mg} \mathrm{L}^{-1}$ ) e capacidade de volatilizar $\mathrm{Hg}^{2+}$. Verificou-se que a capacidade dos micro-organismos volatilizarem o mercúrio não está relacionada a altas concentrações inibitórias mínimas, mas é afetada por concentrações sub-letais de $\mathrm{Hg}$ (II). As bactérias isoladas foram eficientes na redução de $\mathrm{Hg}^{2+}$ a $\mathrm{Hg}^{0}$, com destaque para o alto desempenho de Proteus mirabilis M50C que, em 4 h de incubação, volatilizou $72 \%$ do mercúrio presente no meio.

Estes resultados evidenciam o potencial destes micro-organismos para desenvolvimento de processos de biorremediação em resíduos contaminados com mercúrio. No entanto, são necessários estudos adicionais para elucidar a interação destes micro-organismos com o $\mathrm{Hg}$ (II) e avaliar outros mecanismos de resistência, como a metilação, que poderiam aumentar a toxicidade do material tratado.

\section{REFERÊNCIAS}

1. http://www.chem.unep.ch/mercury/report/GMA-report-TOC.htm, acessada em Janeiro e Novembro 2010.

2. Biester, H.; Gosar, M.; Muller, G.; J. Geochem. Explor. 1999, 65, 195.

3. Maxson, P. Em Dynamics of Mercury Pollution on Regional and Global Scales: Atmospheric Processes and Human Exposures around the World; Pirrone, N.; Mahaffey, K. R., eds.; Springer: New York, 2005, cap. 2.

4. Clarkson, T. W. Em Heavy Metals in the Environment; Sarkar, B., ed.; Marcel Dekker AG: New York, 2002, cap. 13.

5. Ross, M. A.; Health Effects Rev. 1996, 1, 4.

6. ASTDR - Agency for Toxic Substances and Disease Registry; Toxicological Profile for mercury, Atlanta, GA: U.S. Department of Health and Human Services, Public Health Service, 1999.

7. Boening, D. W.; Chemosphere 2000, 40, 1335.

8. Barkay, T.; Miller, S. M.; Summers, A.; FEMS Microbiol. Rev. 2003, 27 , 355.

9. Barkay, T.; Wagner-Döbler, I.; Adv. Appl. Microbiol. 2005, 57, 1.

10. Camargo, F. A. O.; Bento, F. M.; Jacques, R. J. S.; Roesch, L. F. W.; Frankenberer, W, T. Em Tópicos em Ciência do Solo; Ceretta, C. A.; Silva, L. S.; Reichert, J. M., eds; Sociedade Brasileira de Ciência do Solo: Viçosa, 2007, cap. 9.

11. Martins, A. S.; Jesus, M. S.; Lacerda, M.; Moreira, J. C.; Filgueiras, A. L. L.; Barrocas, P. R. G.; Brazilian J. Microbiol. 2008, 39, 307.

12. Ball, M. M.; Curr. Microbiol. 2007, 54, 149.

13. Sambrook, J.; Russel, D. W.; Molecular Cloning: A Laboratory Manual, $3^{\text {rd }}$ ed., Cold Spring Arbor: New York, 2001.

14. Okeke, B. C.; Laymon, J.; Crenshaw, S.; Oji, C.; Biol. Trace Elem. Res. 2008, 123, 229

15. http://www.ncbi.nlm.nih.gov/genbank/, acessada em Novembro 2010.

16. Miles, A. A.; Misra, S. S.; Irwin, J. O.; J. Hygiene 1938, 38, 732.

17. Método EPA 7471B; Mercury in Solid or Semisolid Waste - Manual Cold-Vapor Techinique; http://www.epa.gov/osw/hazard/testmethods/ sw846/pdfs/7471b.pdf, acessada em Novembro 2010.

18. Kannan, S. K.; Krishnamoorthy, R.; Sci. Total Environ. 2006, 367, 341.

19. Wilkinson, L.; Systat 11 Software, University of Illinois, USA, 2004.

20. Horn, J. M.; Brunke, M.; Deckwer, W. D.; Timmis, K. N.; Appl. Environ. Microbiol. 1994, 60, 357.

21. Canstein, H.; Li, Y.; Timmis, K. N.; Deckwer, W. D.; Wagner-Döbler, I.; Appl. Environ. Microbiol. 1999, 65, 5279.

22. Mortazavi, S.; Rezaee, A.; Khavanin. A.; Varmazyar, S.; Jafarzadeh, M.; J. Biol. Sci. 2005, 5, 269.

23. Fortunato, R.; Crespo, J. G.; Reis, M. A. M.; Water Res. 2005, 39, 3511.

24. Chadhain, S. M. N.; Schaefer, J. K.; Crane, S.; Gerben, J.; Zylstra, G. J. Z.; Barkay, T.; Environ. Microbiol. 2006, 8, 1746.

25. Nakamura, K.; Fujisaki, T.; Yoshisada, S.; Nippon Suisan Gakkai Shi 1988, 54, 1359.

26. Nakamura, K.; Iwahara, M.; Furukawa, K.; Clean Prod. Processes 2001, 3, 104 . 
27. Griffin, H. G.; Foster, T. J.; Falkiner, F. R.; Carr, M. E.; Coleman, D. C.; Antimicrob. Agents Chemother. 1985, 28, 413.

28. Henriette, C.; Petitdemange, E.; Raval, G.; Gay, R.; J. Appl. Bacteriol. 1991, 71, 439.

29. Ray, S.; Pahan, K.; Gachhui, R.; Chaudhuri, J.; Mandal, A.; World J. Microbiol. Biotechnol. 1993, 9, 184.

30. Chatziefthimiou, A. D.; Crespo-Medina, M.; Wang, Y.; Vetriani, C.; Barkay, T.; Extremophiles 2007, 11, 469.

31. Barkay, T.; Gillman, M.; Liebert, C.; Appl. Environ. Microbiol. 1990, 56, 1695.

32. Clark, D. L.; Weiss, A. A.; Silver, S.; J. Bacteriol. 1977, 132, 186.

33. Sadhukhan, P. C.; Ghosh, S.; Chaudhuri, J.; Ghosh, D. K.; Mandal, A.; Environ. Pollut. 1997, 97, 71.
34. Ghosh, S.; Sadhukhan, P. C.; Ghosh, D. K.; Chaudhuri, J.; Mandal, A.; J. Appl. Microbiol. 1995, 80, 319.

35. Erbe, J. L.; Taylor, K. B.; Hall, L. M.; Nucleic Acids Res. 1995, 23, 2472.

36. Ghosh, S.; Sadhukhan, P. C.; Ghosh, D. K.; Chaudhuri, J.; Mandal, A.; Bull. Environ. Contam. Toxicol. 1997, 58, 993.

37. Viloca, M. G.; Gao, J.; Karplus, M.; Truhlar, D. G.; Science 2004, 303, 186.

38. Vetriani, C.; Chew, Y. S.; Miller, S. M.; Yagi, J.; Coombs, J.; Lutz, R. A.; Barkay, T.; Appl. Environ. Microbiol. 2005, 71, 220. 